\title{
The mode of action of NSP hydrolysing enzymes in the gastrointestinal tract
}

\author{
O. Simon \\ Institute of Animal Nutrition, Veterinary Faculty, Freie Universität Berlin \\ Brümmerstraße 34, 14195 Berlin, Germany
}

\begin{abstract}
NSP hydrolysing enzymes are used as feed additives especially in cereal based feed for young poultry and to some extent for piglets. The beneficial effects depend on various factors and vary for poultry between 0 and $9 \%$ with regard to weight gain. The mode of action of these feed additives is not well understood. The basis of action is the partial hydrolysis of NSP in the upper digestive tract leading to a decrease of digesta viscosity in the small intestine and to a softening of the so called cage effect. In addition to direct effects on nutrient digestion and absorption, morphological-histological modifications and metabolic responses of the intestinal tissues as well as modifications of quantity and composition of the intestinal microflora seem to be involved in the overall response to the NSP hydrolysing enzymes.
\end{abstract}

KEY WORDS: NSP, enzymes, poultry

\section{INTRODUCTION}

There is no doubt about the usefulness of microbial non starch polysaccharide (NSP) hydrolysing enzymes in rations based on cercals. The positive effects can be measured in terms of performance parameters like daily gain or feed conversion ratio. However, the magnitude of the effects depend very much on animal species, age, type of cereals and the cereal content and solubility of NSP. The most pronounced effects are observed in young poultry. In broiler chickens improvements of between 0 and $9 \%$ have been reported regarding weight gain and of between 0 and $5 \%$ for feed conversion ratio (Jeroch, 1998). In many cases the beneficial effects are higher than would be expected purely on the basis of increased nutrient digestibility or ME content of the ration. 
In the following, an attempt will be made to discuss the various possible modes of action of NSP hydrolysing enzymes. Furthermore, new experimental results from our group will be presented. Since broiler chickens are most sensitive to cereal NSP, emphasis will be put on these specific conditions.

\section{POSSIBLE MODES OF ACTION OF NSP HYDROLYSING ENZYMES}

The basis of action of NSP hydrolysing enzymes in animals is the partial degradation of soluble and insoluble NSP in the upper digestive tract. Since soluble NSP produces viscosity in aqueous solutions, the degradation of this fraction leads to a decrease in digesta viscosity. This effect was observed in almost all experiments with broilers and piglets, in which digesta viscosity was measured. In a parallel process the same enzymes hydrolyse partially insoluble NSP, which are primarily contained in cell walls, and transfer them into a soluble form. This kind of transformation was shown to take place in the digestive tract of broilers (Pettersson and Åman, 1989) as well as of piglets (Haberer, 1997). The "locking in" of nutrients in the cell lumen by NSP of the cell walls is sometimes called "cage effect". Generally, the beneficial effects of NSP hydrolysing enzymes are explained by decreasing digesta viscosity on the one hand and by softening the cage effect on the other hand. Both are considered in Figure 1, however, the mode of action seems to be rather complex.

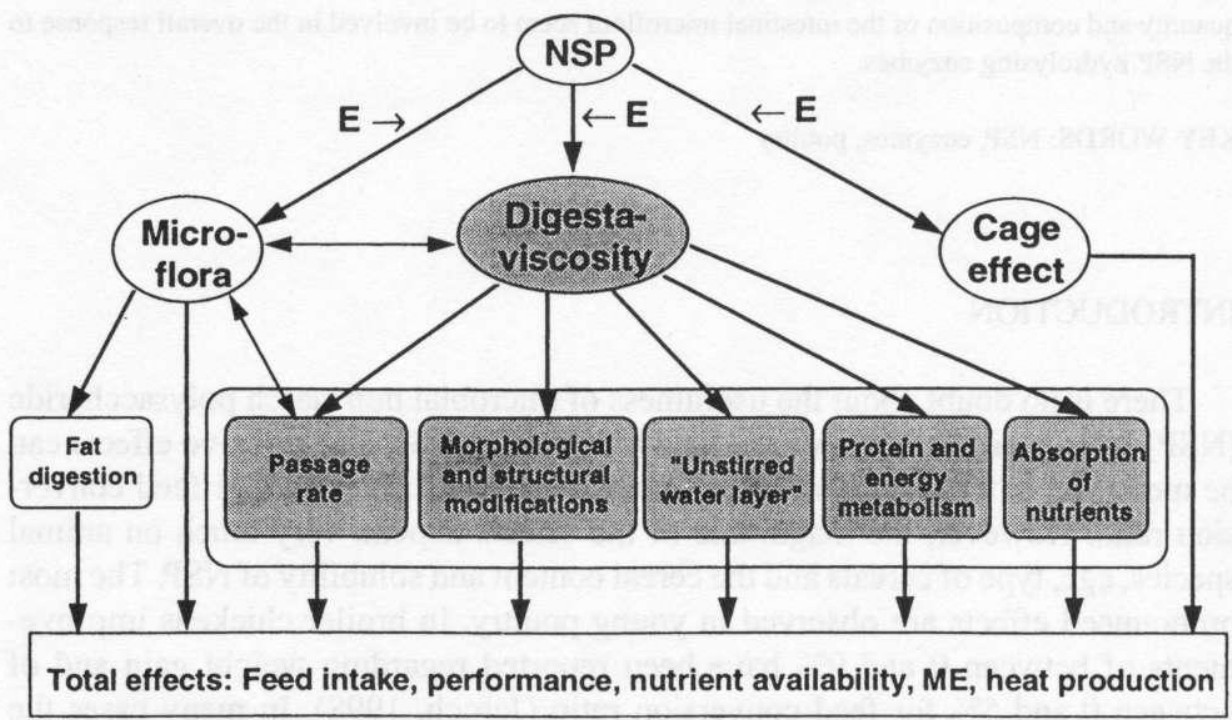

Figure 1. Assumed mode of action of non starch polysaccharides (NSP) and of NSP-hydrolysing enzymes $(E \rightarrow)$ 
Action via softening the cage effect

The best indicator for the contribution of the cage effect to the total effect of the enzymes seems to be the precaecal starch digestibility, since starch is the main nutrient contained in the endosperm cells of cereals. According to the measurements of Almirall et al. (1995) in broilers fed diets based on barley, the precaecal digestibility of starch was improved by addition of ß-glucanases (Figure 2). However, because of the very high digestibility of starch without enzyme addition (95\%) there is very limited room for further improvement. The improving effect of NSP hydrolysing enzymes on precaecal starch digestion is even smaller in piglets (Inborr et al., 1993). Thus, the action of NSP hydrolysing enzymes via softening the cage effect seems to make only a small contribution to the overall effect (improved starch digestibility by 1 to $2 \%$ ).

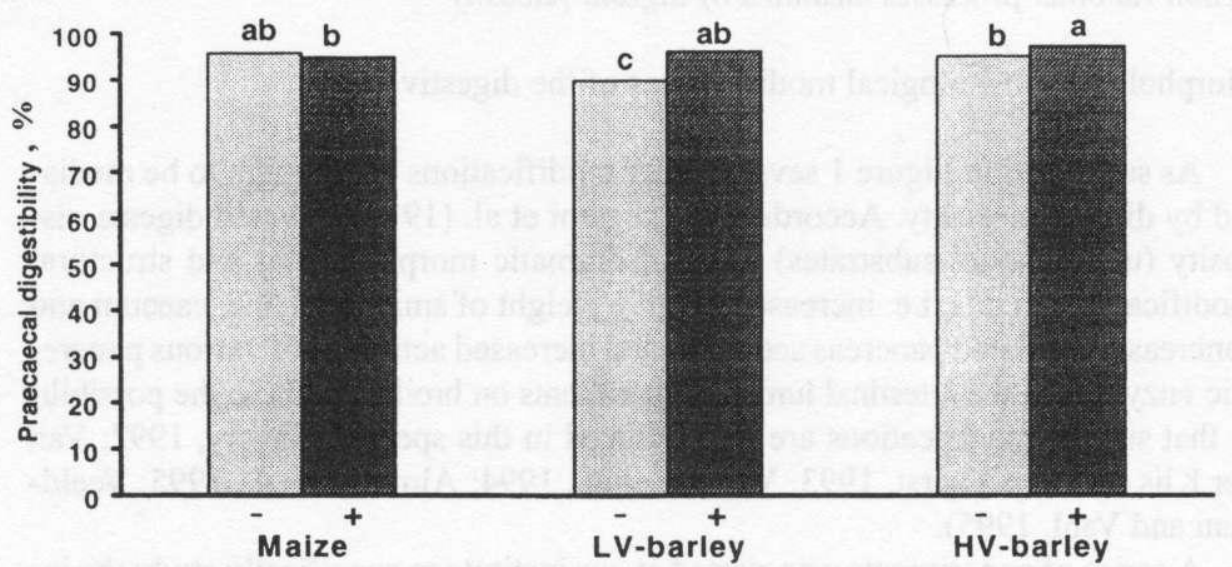

$-/+=$ without/with $\beta$-glucanase

Basic diet composition, $\mathrm{g} / \mathrm{kg}$ : cereals 600 ; soyabean meal 300; soya oil 35 LV-barley: extract viscosity $7.2 \mathrm{mPas}$

HV-barley: extract viscosity $13.3 \mathrm{mPas}$

Figure 2. Precaecal digestibility of starch in broilers (3 weeks); diet based on maize and barley, respectively; effects of $\beta$-glucanase supplementation (according to Almirall et al., 1995)

Action via nutrient digestibility due to decreased digesta viscosity

Improved nutrient digestibility due to decreased digesta viscosity is mainly explained by:

- facilitated diffusion of substrates, digestive enzymes and products of digestion;

- improved convection of the intestinal content by contractions, and

- improved contact of absorbable nutrients with the surface of enterocytes. 
In contrast to the cage effect, processes of this type are valid for all nutrients in the diet, independent of their origin, i.e. not only nutrients from cereals are affected but also from other components of the ration. Fat digestibility suffers the most pronounced impairment by high digesta viscosities. When rye based diets (leading to high digesta viscosities) were offered to broilers, fat digestibility was improved by between 5 and $30 \%$ by the addition of xylanase (Dänicke et al., 1997). The effects on digestibility depend mainly on the melting point, which is high for fats with a high melting point (tallow) and low for e.g. soya oil. Digesta viscosity influences the digestibility of other nutrients to a far lesser extent. Especially in diets with added fat, the improvement in fat digestibility by enzyme addition may considerably increase the ME content of the ration. In the experiment mentioned above, this improvement was more than $1 \mathrm{MJ} \mathrm{ME} \mathrm{N}_{\mathrm{N}}$.

Action via other processes mediated by digesta viscosity

Morphological-histological modifications of the digestive tract

As suggested in Figure 1 several other modifications are thought to be mediated by digesta viscosity. According to Ikegami et al. (1990) elevated digesta viscosity (using model substrates) induced dramatic morphological and structural modifications in rats, i.e. increased relative weight of small intestine, caecum and pancreas, stimulated pancreas secretion and increased activities of various pancreatic enzymes in the intestinal lumen. Experiments on broilers point to the possibility that similar modifications are also induced in this species (Savory, 1992; Van der Klis and Van Voorst, 1993; Viveros et al., 1994; Almirall et al., 1995; Veeldman and Vahl, 1995).

A series of experiments was started at our institute to specifically study the influence of intestinal viscosity on the development of the digestive tract in broilers. For this purpose a basal diet was formulated which produced very low digesta viscosities in the jejunum and ileum ( 1.7 an $3.3 \mathrm{mPas}$, respectively). The main constituents of this diet were maize, soya protein isolate and crystalline cellulose. In the first experiment, digesta viscosity was modulated by gradually replacing the maize with rye (up to $75 \%$ ). Digesta viscosity was measured at an age of 21 days, along with the weight, length and protein contents of the digestive tract. As can be seen in Figure 3, there was a highly positive correlation between the relative weight of the intestine (which was increased by up to $50 \%$ ) and the viscosity of the jejunal content $(r=0.97)$. Similar correlations were observed between digesta viscosity and the total weight of the gastrointestinal tract and as well as for the length of the intestine. In the second experiment viscosity was modulated in the same range by gradually replacing crystalline cellulose with soluble cellulose (carboxy methyl cellulose $=\mathrm{CMC}$ ). Using this model substrate exactly the same correlations were 


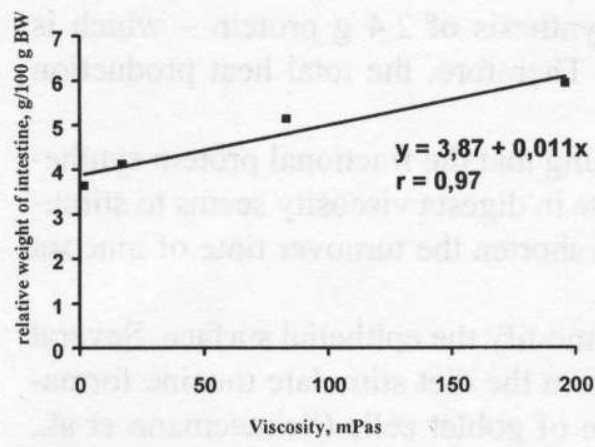

Figure 3. Relationship between digesta viscosity in the jejunum and the relative weight of intestine in broilers (Digesta viscosity was modified by gradual inclusion of rye)

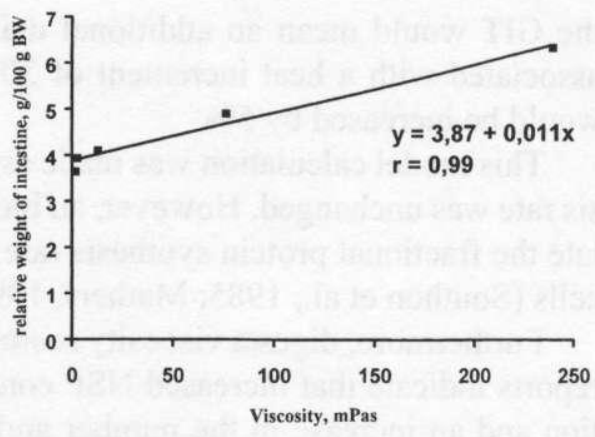

Figure 4. Relationship between digesta viscosity in the jejunum and the relative weight of intestine in broilers (Digesta viscosity was modified by gradual inclusion of $\mathrm{CMC}$ )

found between jejunal viscosity and the weight of intestine (Figure 4) and the other parameters. In addition, other model substrates (guar gum, oat spelt xylan) act in the same way. At very high viscosities the weight of the intestine was almost doubled. It can therefore be concluded, that the observed modifications are simply based on digesta viscosity and not on other constituents of rye. Since the protein content of the intestinal tissue was not influenced, the increase in weight of the intestinal tract means also that there is an increased amount of protein present in the tissues of the gastrointestinal tract (GIT).

In a model calculation we have tried to estimate the influence of an assumed $30 \%$ increase in the amount of protein in the gastrointestinal tract on the energy metabolism (Table 1). Due to the very high turnover rate of the proteins in the intestinal tract, in an animal of $1 \mathrm{~kg}$ body weight the increased protein content of

TABLE 1

Model calculation for the effect of an increase of the amount of protein in the GIT by $30 \%$ on energy metabolism (calculated for $1 \mathrm{~kg} \mathrm{BW}$ )

\begin{tabular}{lcccr}
\hline & $\begin{array}{c}\text { Amount of } \\
\text { protein } \\
\mathrm{g}\end{array}$ & $\begin{array}{c}\text { Fractional } \\
\text { synthesis rate } \\
\% \mathrm{x} \mathrm{d}^{-1}\end{array}$ & $\begin{array}{c}\text { Amount of } \\
\text { synthesised protein } \\
\mathrm{g} \mathrm{x} \mathrm{d}^{-1}\end{array}$ & $\begin{array}{c}\text { GIT } \\
\text { Total body }\end{array}$ \\
Skeletal muscles & 160 & 23 & 36.8 & 39.2 \\
GIT & 88 & 10 & 8.8 & 8.8 \\
Heat production, $\mathrm{kJ} \mathrm{x} \mathrm{d}^{-1}$ & 625 & 70 & 7.8 & 10.2 \\
& & GIT $130 \%$ & $+30 \mathrm{~kJ}=\mathrm{ca} .+5 \%$ \\
\hline
\end{tabular}

a based on various references 
the GIT would mean an additional daily synthesis of $2.4 \mathrm{~g}$ protein - which is associated with a heat increment of $30 \mathrm{~kJ}$. Therefore, the total heat production would be increased by $5 \%$.

This model calculation was made assuming that the fractional protein synthesis rate was unchanged. However, an increase in digesta viscosity seems to stimulate the fractional protein synthesis rate and shorten the turnover time of mucosa cells (Southon et al., 1985; Mathers, 1995).

Furthermore, digesta viscosity seems to modify the epithelial surface. Several reports indicate that increased NSP contents in the diet stimulate mucine formation and an increase in the number and size of goblet cells (Schneemann et al,, 1982; Satchithandam et al., 1990; Viveros et al., 1994). The intensity of mucine formation may influence the thickness of the so called unstirred water layer, which is expected to be especially important for the movement of fat micelles during the absorption process.

\section{Action via modification of the intestinal microflora}

It is frequently claimed that modifications of the intestinal microflora are involved in the effects of various feed additives; similar discussions concerning the microflora have also been made in attempting to explain the mode of action of NSP hydrolysing enzymes. However, almost no experimental data are available on this matter. Theoretically, enzyme addition has the potential to modify quantity and composition of the microbial population in the digestive tract by various mechanisms. Not all modifications are connected to the viscosity decreasing action. Such mechanisms are:

- accelerated passage rate of digesta - may shift the bacterial population towards genera with shorter generation time,

- improved absorption of nutrients and shift of the site of absorption towards the upper segments - may mean a shortage of substrates for bacterial growth especially in the distal segments,

- reduced length of the intestine - area for tissue associated bacteria is restricted and reduces in this way the number of microbes in a segment,

- reduced viscosity and modified mucine formation -.. may modify the adhesion conditions for tissue associated bacteria,

- partial degradation and solubilisation of insoluble NSP to oligomers (and monomers) improves the availability of these substrates for specific microbial populations in the upper intestinal tract,

- changes in the quantity and composition of the intestinal microbial population may influence the host animal via nutricnt availability, formation of metabolic products (toxins) or colonisation of enterocytes. Furthermore, intestinal bacteria are known to produce enzymes (cholyl taurin hydrolases) which deconju- 
gate bile salts. The activity of these enzymes was increased 10 to 20 times in the ileal digesta of broilers when a rye based diet rather than a maize based diet was fed (Feighner and Dashkevicz, 1988). It remains unclear whether or not the improvement in fat digestion when xylanase is added to rye based diets (Dänicke et al., 1997) is based on modifications of the bacterial cholyl taurin hydrolase activity,

- in a recent study of our group (Vahjen et al., 1998) the colonisation of lactobacilli, enterobacteria and facultative anaerobic gram positive cocci was moni-
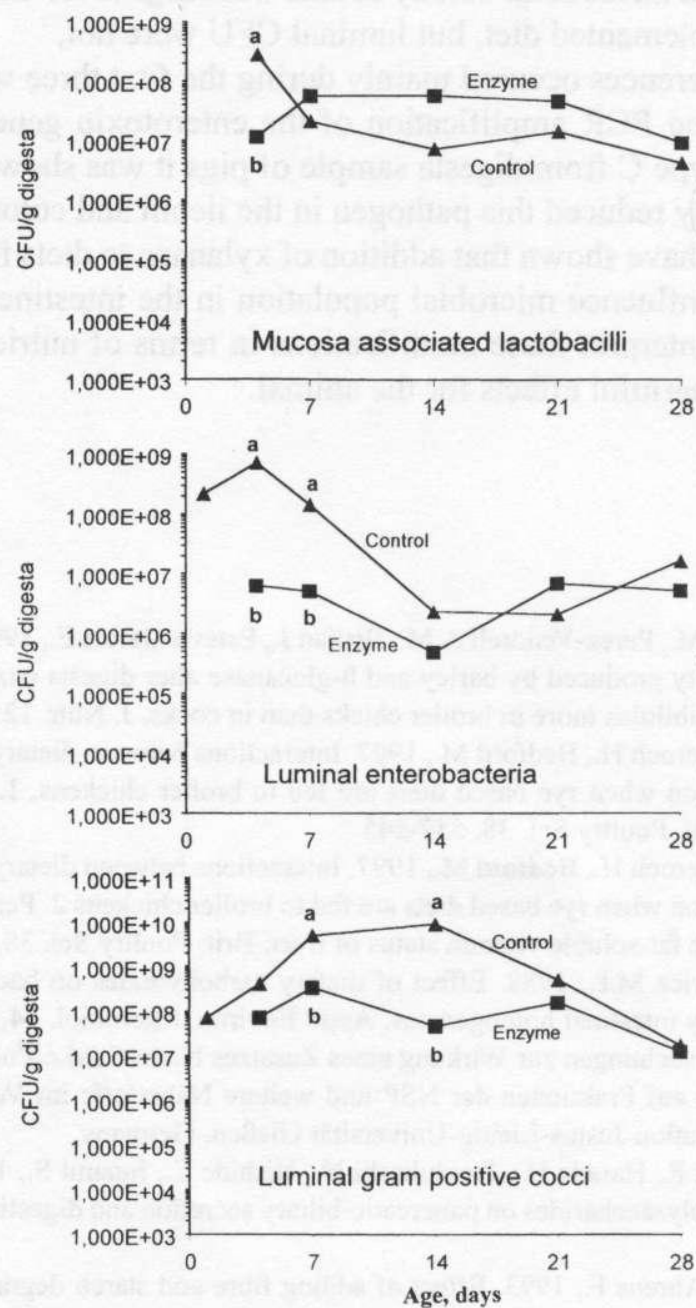

Figure 5. Development of mucosa associated lactobacilli, luminal enterobacteria and luminal gram positive cocci in the jejunum of broilers 
tored in broilers from day 1 to 28 post-hatching. The diet was based on wheat (variety Aron; $4.25 \mathrm{mPas}$ extract viscosity), soyabean meal and fish meal. One group of animals received the unsupplemented diet and a second one the diet supplemented with a xylanase (Thermomyces longinosus; $1200 \mathrm{IU} / \mathrm{kg}$ ). The duodenum, jejunum and ileum were studied separately and luminal and mucosa associated flora were differentiated. Some of the results are presented in Figure 5. The findings of this study can be summarised as follows:

- enterobacteria and total gram positive cocci in luminal and mucosa samples were reduced significantly by the enzyme addition,

- mucosa associated lactobacilli colony counts were higher for animals receiving the xylanase supplemented diet, but luminal CFU were not,

- the observed differences occured mainly during the first three weeks of life. Furthermore, using PCR amplification of the enterotoxin gene from Clostridium perfringens, type $\mathrm{C}$ from digesta sample of pigs it was shown that xylanase addition significantly reduced this pathogen in the ileum and colon.

Thus, our results have shown that addition of xylanase to diets for broilers (and pigs) significantly influence microbial population in the intestine, but at present we are not able to interpret these modifications in terms of nutrient economy or other beneficial or harmful effects for the animal.

\section{REFERENCES}

Almirall M., Francesch M., Perez-Vendrell A.M., Brufau J., Esteve-Garcia E., 1995. The differences in intestinal viscosity produced by barley and $\beta$-glucanase alter digesta enzyme activities and ileal nutrient digestibilities more in broiler chicks than in cocks. J. Nutr. 125, 947-955

Dänicke S., Simon O., Jeroch H., Bedford M., 1997. Interactions between dietary fat type and xylanase supplementation when rye based diets are fed to broiler chickens. 1. Physico-chemical chyme features. Brit. Poultry Sci, 38, 537-545

Dänicke S., Simon O., Jeroch H., Bedford M., 1997. Interactions between dietary fat type and xylanase supplementation when rye based diets are fed to broiler chickens 2 . Performance, nutrient digestibility and the fat-soluble vitamin status of liver. Brit. Poultry Sci. 38, 546-556

Feighner S.D., Dashkevicz M.P., 1988. Effect of dietary carbohydrates on bacterial cholytaurine hydrolase in poultry intestinal homogenates. Appl. Environ. Microbiol. 54, 337-342

Haberer B., 1997. Untersuchungen zur Wirkung eines Zusatzes Nicht-Stärke-Polysaccharid (NSP)spaltender Enzyme auf Fraktionen der NSP und weitere Nährstoffe im Verdauungstrakt von Schweinen. Dissertation Justus-Liebig-Universität Gießen, Germany

Ikegami S., Tsuchihashi F., Harada H., Tsuchihashi N., Nishide E., Innami S., 1990. Effect of viscous indigestible polysaccharides on pancreatic-biliary secretion and digestive organs in rats. J. Nutr. 120, 353-360

Inborr J., Schmitz M., Ahrens F., 1993. Effect of adding fibre and starch degrading enzymes to a barley/wheat based diet on performance and nutrient digestibility in different segments of the small intestine of early weaned pigs. Anim. Feed Sci. Technol. 44, 113-127 
Jeroch H., 1998. In: Jahrbuch für die Geflügelwirtschaft. Verlag Eugen Ulmer, Stuttgart

Mathers J.C.. 1995. Dietary polysaccharides, crypt cell proliferation and apoptosis. Implication for colon cancer. DIfE-Workshop, Proceedings

Pettersson D., Åman P., 1989. Enzyme supplementation of a poultry diet containing rye and wheat. Brit. J. Nutr. 62, 139-149

Satchithanandam S., Vargofcak-Apker M., Calvert R.J., Leeds A.R., Cassidy M.M., 1990. Alteration of gastrointestinal mucin by fibre feeding in rats. J. Nutr. 120, 1179-1184

Savory C.J., 1992. Gastrointestinal morphology and absorption of monosaccharides in fowls conditioned to different types and levels of dietary fibre. Brit. J. Nutr. 67, 77-89

Schneemann B.O., Richter B.D., Jacobs L.R., 1982. Response to dietary wheat bran in the exocrine pancreas and intestine of rats. J. Nutr. 112, 283-286

Southon S., Livesey G., Gee J.M., Johnson I.T., 1985. Differences in intestinal protein synthesis and cellular proliferation in well-nourished rats consuming conventional laboratory diets. Brit. J. Nutr. 53, 87-95

Vahjen W., Gläser K., Schäfer K., Simon O., 1998. Influence of xylanase supplemented feed on the development of bacterial groups in the intestinal tract of broiler chicks. J. Agric. Sci., Camb. (in press)

Van der Klis J.D., Van Voorst A., 1993. The effect of carboxy methyl cellulose (a soluble polysaccharide) on the rate of marker excretion from the gastrointestinal tract of broilers. Poultry Sci. $72,503-512$

Viveros A., Brenes A., Pizarro M., Castano M., 1994. Effect of enzyme supplementation of a diet based on barley, and autoclave treatment, on apparent digestibility, growth performance and gut morphology of broilers. Anim. Feed Sci. Technol. 48, 237-251 